\title{
Advances and Prospects in Stem Cells for Cartilage Regeneration
}

\author{
Mingjie Wang, ${ }^{1}$ Zhiguo Yuan, ${ }^{1}$ Ning Ma, ${ }^{1}$ Chunxiang Hao, ${ }^{2}$ Weimin Guo, ${ }^{1}$ \\ Gengyi Zou, ${ }^{3}$ Yu Zhang, ${ }^{1}$ Mingxue Chen, ${ }^{1}$ Shuang Gao, ${ }^{4}$ Jiang Peng, ${ }^{1}$ Aiyuan Wang, \\ Yu Wang, ${ }^{1}$ Xiang Sui, ${ }^{1}$ Wenjing Xu, ${ }^{1}$ Shibi Lu, ${ }^{1}$ Shuyun Liu, ${ }^{1}$ and Quanyi Guo ${ }^{1}$ \\ ${ }^{1}$ Institute of Orthopaedics, Chinese PLA General Hospital, Beijing Key Lab of Regenerative Medicine in Orthopaedics, \\ Key Laboratory of Musculoskeletal Trauma \& War Injuries, PLA, 28 Fuxing Road, Haidian District, Beijing 100853, China \\ ${ }^{2}$ Anesthesiology Department, Chinese PLA General Hospital, 28 Fuxing Road, Haidian District, Beijing 100853, China \\ ${ }^{3}$ Medical College, Nankai University, Tianjin, 300071, China \\ ${ }^{4}$ Center for Biomedical Material and Tissue Engineering, Academy for Advanced Interdisciplinary Studies, \\ Peking University, Beijing 100871, China
}

Correspondence should be addressed to Shuyun Liu; clear_ann@163.com and Quanyi Guo; doctorguo_301@163.com

Received 22 July 2016; Revised 24 November 2016; Accepted 26 December 2016; Published 26 January 2017

Academic Editor: Jianying Zhang

Copyright (c) 2017 Mingjie Wang et al. This is an open access article distributed under the Creative Commons Attribution License, which permits unrestricted use, distribution, and reproduction in any medium, provided the original work is properly cited.

The histological features of cartilage call attention to the fact that cartilage has a little capacity to repair itself owing to the lack of a blood supply, nerves, or lymphangion. Stem cells have emerged as a promising option in the field of cartilage tissue engineering and regenerative medicine and could lead to cartilage repair. Much research has examined cartilage regeneration utilizing stem cells. However, both the potential and the limitations of this procedure remain controversial. This review presents a summary of emerging trends with regard to using stem cells in cartilage tissue engineering and regenerative medicine. In particular, it focuses on the characterization of cartilage stem cells, the chondrogenic differentiation of stem cells, and the various strategies and approaches involving stem cells that have been used in cartilage repair and clinical studies. Based on the research into chondrocyte and stem cell technologies, this review discusses the damage and repair of cartilage and the clinical application of stem cells, with a view to increasing our systematic understanding of the application of stem cells in cartilage regeneration; additionally, several advanced strategies for cartilage repair are discussed.

\section{Introduction}

Cartilage defects, the most common disease of joints, can cause swelling, pain, and subsequent loss of joint function [1]. The capacity for cartilage self-repair is limited due to its unique structure, as it lacks blood supply, nerves, and lymphangion; cartilage absorbs supplements mainly from the synovial fluid. Therefore, traumatic articular cartilage injury and early osteoarthritis (OA) cause pain, accelerate arthrosis, and cause severe dysfunction. Meniscus injury results in pain to patients, limits their movement, and can accelerate the occurrence and development of OA. Intervertebral disc cartilage injury is one of the leading causes of chronic back pain [2]. Cartilage injury and subsequent tissue degeneration can cause long-term chronic diseases; moreover, such damage consumes large amounts of medical resources [3]. However, the field of regenerative medicine has shown promising developments in the repair of damaged cartilage.

Seed cells are the key components of regenerative medicine, which leads to healing. Autologous cartilage is the gold standard for cartilage seed cells in regenerative medicine [4]. Autologous chondrocyte implantation (ACI) has been applied widely with confirmed clinical effects in terms of repairing cartilage defects $[5,6]$. As the donor source for autologous chondrocytes is limited, cells must be amplified in monolayers in vitro before implantation to meet the requirements of repair. However, the expansion of monolayers can cause rapid chondrocyte dedifferentiation, leading to loss of the original cell phenotype [7]. Compared with normal cartilage cells, dedifferentiated chondrocytes are more likely to generate fibrous cartilage instead of hyaline cartilage; the latter has better biomechanical properties and is 
more durable. However, autologous cartilage transplantation requires a second surgical operation and increases the risk of injury to healthy cartilage in the donor area. Chondrocytes maintain their phenotype when cultured in vivo with cytokines in three-dimensional (3D) cultures [8, 9]. However, the clinical application of autologous chondrocyte repair is limited.

Stem cells have the potential for self-renewal and differentiation into multiple cell lines. Stem cells can be divided into three main categories: embryonic stem cells (ESCs), induced pluripotent stem cells (iPSCs), and adult stem cells [10]. ESCs are derived from the inner cell mass of blastocyststage embryos [11]. iPSCs can be derived from somatic cells via genetic reprogramming [12]. Adult stem cells are isolated from various adult tissues [13]. ESCs and iPSCs are pluripotent cells that differentiate into cells of all three lineages: ectoderm, mesoderm, and endoderm [14]. Adult stem cells are subdivided into multipotent and unipotent stem cells; unipotent cells can differentiate only into one cell type, such as satellite stem cells or epidermal stem cells. Multipotent cells can differentiate into several cell types in one lineage; for example, mesenchymal stem cells (MSCs) can differentiate into osteoblasts, chondrocytes, and fat cells [13]. The capacity for self-renewal and the potential for multiple differentiation of stem cells, such as ESCs, iPSCs, and MSCs, have been studied widely in the field of tissue regeneration. Furthermore, studies involving MSCs have been fully applied in the clinical setting [15]. In this review, we focus on the cartilage injury mechanism and treatment strategies and studies of stem cells in the field of cartilage regeneration.

\section{Characterization of Cartilage Stem Cells}

Based on the continuous damage-repair theory, Dowthwaite et al. were the first to describe cartilage stem cells (CSCs) on the surface of articular cartilage [16]. They discovered that CSCs and fibronectin have a close interrelationship. Furthermore, they showed that CSCs have high colonyforming efficiency and can express Notch 1, which plays an important role in the early steps in notch signaling, inducing chondrogenesis [17]. CSCs also exist in patients with endstage OA [18], and cells with chondrogenic potential can migrate rapidly into damaged cartilage to downregulate the expression of Runx-2, an osteogenic transcription factor, and enhance the expression of Sox-9, a chondrogenic transcription factor. By regulating Runx-2 and Sox-9 to inhibit osteogenesis in the damaged cartilage, CSCs can facilitate chondrogenesis to improve cartilage self-repair [19]. The matrix synthesis potential of CSCs can be increased without altering their migratory capacity. While cartilage cells usually exist in the surface of cartilage $[16,18]$, Yu et al. found in 2014 that CSCs also exist in the deep zone of cartilage [20]; one-third of the surface area contains more cartilage stem cells than two-thirds of the deep area. Different regions have distinct gene expression patterns and specific differentiation potential, and these features may be related to the unique properties of the superficial and deep zone stem cells, thereby participating in articular cartilage homeostasis. Zhou et al. showed that, compared with chondrocytes, cartilage stem cells can overexpress chemokines such as interleukin-8 (IL8 ) and C-C motif ligand 2 (CCL-2). However, during pellet cultivation, the content of glycosaminoglycan (GAG) is lower than that in cartilage cells [21]. CSCs overexpress chemokines, which increases immune cells. Furthermore, they mediate inflammation during the processes of cartilage damage and repair. After chondrogenic induction, collagen type II and aggrecan can be detected (but not collagen type X), which differs from bone marrow stem cells (BMSCs) [22]. However, collagen type $\mathrm{X}$ is closely related to cartilage degeneration and aging [23]. Meanwhile, inducing BMSCs and CSCs into chondrocytes in vitro is more likely to lead to cell hypertrophy. Several studies have reported that CSCs have a better effect than synoviocytes in terms of cartilage induction in vitro [21]. These results suggest that CSCs might have a stronger potential than MSCs (BMSCs and synoviocytes) for cartilage induction.

In 2016, Jiang et al. further studied human cartilagederived stem cells and their potential in the clinical application of cartilage tissue repair [24]. Using in vitro and in vivo experiments, they compared the chondrogenic ability of cartilage stem cells that had been cultured under different conditions. They found that, in the low-density, lowglucose 2-dimensional (2DLL) medium, cartilage stem cells can differentiate into cartilage spontaneously, without being induced, which supports potential for clinical applications. One of the in vivo studies included 15 patients undergoing cartilage repair surgery with cartilage progenitor cells, each of whom had a $6-13 \mathrm{~cm}^{2}$ area of damage. Recently, Huang et al. found stem cells in the meniscus [25]. They compared several characteristics of meniscus-derived stromal cells, autologous BMSCs, and fibrochondrocytes, including their morphology, proliferation, colony formation, immunocytochemistry, and multidifferentiation. Both meniscus-derived stromal cells and BMSCs have a marker related to stem cells. In addition, they can differentiate into osteocytes, adipocytes, and chondrocytes in vitro. Compared with BMSCs, however, more meniscus-derived stromal cells can differentiate into cartilage, which means that they are more effective at chondrogenesis. Sang et al. isolated nucleus pulposus stem cells (NPSCs) and annulus fibrosus stem cells (AFSCs) from intervertebral discs [26]. Both disk stem cells can form colonies and express stem cell markers during early cell passages, and each type of stem cell has different characteristics that reflect the tissue function that they represent.

There is a gap between the cell phenotype and the potential for regeneration between regular articular cartilage and induced cartilage formed by differentiated cartilage stem cells. This difference affects the ability to form hyaline cartilage of high quality. However, compared with most stem cells, cartilage stem cells have a superior potential for cartilage regeneration [27]. Studies of CSCs are still in the early stage, and further studies are needed to understand their role in cartilage regeneration. Autologous stem cells face similar problems to those of $\mathrm{ACI}$, such as risk of injury to healthy cartilage, the requirement for a second operation, and a series of issues that present during cartilage defect repair. 
In overcoming problems of cellular immune rejection or cells with low immunogenicity, allogeneic cartilage stem cells present an attractive approach for cartilage defect repair [24].

\section{Chondrogenic Differentiation of Stem Cells}

Stem cells have the potential for multiple differentiation and self-replication, making them an ideal choice for use as seed cells in cartilage tissue engineering. An important step in the tissue engineering of cartilage is the induction of stem cells (including ESCs, iPSCs, and adult stem cells) into chondrocytes. Through tissue engineering, ESCs can be induced to form chondrocytes that repair cartilage damage [54]. Because undifferentiated ESCs have a high risk for tumorigenicity and teratoma, it is important to use stable and effective culture conditions to amplify ESCs and induce them to differentiate into a specific chondrogenic lineage [55]. Many strategies have been applied to induce ESC differentiation into chondrogenic lineage [56], including (1) embryoid body formation, a strategy that imitates the early stage of embryonic development as the ectoderm, mesoderm, and ectoderm; (2) differentiation into MSCs, a method that takes advantage of the immune exemption features and higher security of MSCs, which facilitates cartilage tissue engineering; and (3) the use of growth factors and cytokines such as members of the TGF- $\beta$ family (e.g., TGF- $\beta 1$ and TGF- $\beta 2$ ), BMP family (e.g., BMP-2, BMP-4, and BMP-6), PDGF-bb, IGF-1, and sonic hedgehog protein (SHH). Several other strategies have been used that are similar to adult stem cell strategies, such as chondrocyte or fibrocyte coculture, $3 \mathrm{D}$ culture to change the cell microenvironment, hypoxia induction, and mechanical stimulation [54].

iPSCs can be derived from somatic cells through genetic reprogramming [57]. ESCs and iPSCs display self-replication and pluripotency, with iPSCs having distinct ethical advantages over ESCs. Originally, four factors-octamer-binding transcription factors 3 and 4 (Oct3/4), Kruppel-like factor 4 (Klf4), v-myc avian myelocytomatosis viral oncogene homolog (c-myc), and Sox-2-were identified in a mouse model as being involved in changing fibroblasts into iPSCs [57]. Of the four, Oct $3 / 4$ and Sox- 2 are transcription factors, while Klf4 and c-myc are genes that are upregulated in tumors [10]. This discovery was a breakthrough in the stem cell field and provided a new tool in gene therapy and tissue engineering. Since then, somatic cells, fibroblasts, and chondrocytes have been reprogrammed successfully to become iPSCs and differentiate into chondrogenic lineage [58]. iPSCs derived from fibroblasts of skin can be induced into chondrocytes. Additionally, based on the HLA phenotype, it is possible to build an iPSC library that can provide allogeneic iPSCs. Cells from the library can be induced into chondrocytes to regenerate cartilage. This strategy is advantageous because it limits costs while offering wide coverage [59]. Compared with other iPSC lines, the iPSC line derived from chondrocytes can express higher quantities of aggrecan gene products [60]. In addition, the expression of cartilage-related genes does not differ from that of chondrogenic markers. iPSC technology offers a new and safe way to repair cartilage. This process will require optimization of the production process, a better understanding of the biological characteristics, and establishment of a differentiation strategy to achieve a productive and functional chondrocyte-like cell line.

MSCs are considered to be the most promising cells for cartilage regeneration by cell transplantation, and they have been applied clinically [61]. MSCs that differentiate into chondrocytes are induced by molecules, cytokines (which are mainly growth factors), and the microenvironment in cultured cells. Chondrogenesis from MSCs can be divided into three stages [62]. First, the stem cells condense and cellto-cell interactions occur. MSCs begin to express adhesion molecules, such as $\mathrm{N}$-cadherin, tenascin- $\mathrm{C}$, and neural cell adhesion molecule (N-CAM). The condensation of MSCs is crucial during the early stage of chondrogenesis. Then, transcription mediators are activated, such as bone morphogenetic proteins (BMPs), Sox-9, PTHrP/IHH, and the FGF signaling pathways [63]. Finally, extracellular matrix (ECM) and precartilage cells are formed. Following the formation of precartilage, the perichondrial cells proliferate rapidly, secrete more ECM, and differentiate fully.

Mature chondrocytes localize at cartilage tissue. The ability of chondrocytes to maintain their phenotype is closely related to the conditions of their local microenvironment [64], including the type of 3D extracellular matrix, hypoxic conditions, mechanical loading, and specialized morphological structure [65]. Similarly, MSCs require specific conditions to differentiate into chondrocytes. The coculture of chondrocytes and MSCs is a new way to culture cells so that chondrocytes can induce MSCs, and MSCs can promote chondrocyte proliferation [66].

\section{Cartilage Injury Mechanisms and Treatment}

4.1. Articular Cartilage. Articular cartilage damage can occur through violent injury, chronic inflammatory disease such as rheumatoid arthritis (RA), or degenerative joint diseases such as OA. Several important mechanisms related to the occurrence and development of cartilage damage and degeneration include inflammation reactions that change the chondrocyte phenotype, the loss of ECM components, and damage and refactoring of the cartilage-bone unit [67]. Inflammatory cytokines play an important role in the progression of cartilage degeneration, and blocking some inflammatory cytokines can delay cartilage degeneration. Inflammatory cytokines are secreted by mononuclear cells, which induce hyperplasia of the synovial membrane [68]. Studies suggested that inflammatory reactions exist only in the synovial tissue, but recent studies have also confirmed the occurrence of cartilage inflammation. Chondrocytes are separated from the degenerated articular cartilage hypertrophy in vitro [69]. The change in the phenotype of chondrocytes prevents them from producing cartilage ECM components-such as proteoglycan and collagen type II, which are required to maintain the biological characteristics of cartilage cells. Conversely, chondrocytes can reduce the proportion of proteoglycan and produce more collagen type $\mathrm{X}$, which is related to cell 
senescence [70]. Articular cartilage and subchondral bone form an inseparable organic cartilage-bone unit; in fact, damage and degeneration of articular cartilage are certain to cause subchondral bone destruction [71]. Moreover, the separation of articular cartilage and subchondral bone causes osteochondritis dissecans (OCD).

Treatment strategies for articular cartilage injuries include palliative treatment strategies, arthroscopic debridement and arthroplasty treatment strategies, and regenerative treatment strategies.

Palliative treatment strategies mainly include physiotherapy (thermal and electrical stimulation, high-intensity ultrasound, pulsed electromagnetic fields, millimeter waves, ultrasound, and low-level laser therapy), weight loss and muscle strengthening programs, and medications (glucosamine and chondroitin are used as treatments for cartilage defects, and although neither drug is used to alleviate the symptoms, they have been proven to reverse or suspend the progression of cartilage degeneration). Injection treatment strategies, compared with surgery, offer convenience and low risk. The injected material can have a direct effect on articular cartilage and remain in the articular cavity for a long time. Due to these characteristics, many different studies on articular cavity injection treatment strategies have been reported, pertaining, for example, to platelet-rich plasma (PRP) [72, 73], drug delivery strategies [74], polyphenol stabilization of cartilage collagen against degradation, action of the IL-1 receptor as an antagonist against lubricin metabolism and cartilage degeneration, the activities of rapamycin [75], alendronate [76], hyaluronic acid [77], bone morphogenetic protein-7 [78], and lidocaine [79], which reduce live chondrocytes and change the gene expression of COL II and aggrecan, and intra-articular steroid injections [80]. Arthroscopic debridement is used mainly in the middle-late stage of articular cartilage degeneration. Although arthroscopic debridement as a treatment of knee OA has been widely adopted as a surgical option, its efficacy has been controversial [81-83]. Arthroscopic debridement includes articular cavity flushing, meniscus partial nephrectomy, the removal of loose bodies, removal of the synovial membrane, chondroplasty, and osteophyte resection. Studies have shown that arthroscopic debridement can relieve short-term symptoms, especially in patients with $\mathrm{OA}$ with acute pain and patients with loose bodies in the articular cavity. Arthroplasty has been used widely in the treatment of late-stage articular cartilage lesions, with replacement usually being of the knee or hip [84].

4.2. Meniscus. The meniscus is composed of lateral fiber and medial transparent chondroid tissues. It disperses the pressure between the tibia platforms and the femoral condyle. Damage to the meniscus is often due to direct violence and can also reflect chronic degeneration [85]. Like cartilage injury, meniscus injury shows limitations in self-repair. Only the lateral fiber, which has a blood supply, can be stitched, but damage to this fiber is quite rare. Apart from causing restricted movement of the knee joint, meniscus injury also changes the mechanical structure of the joint, accelerating cartilage degeneration therein. The most commonly used treatment for meniscus injury is arthroscopic suture or resection. This procedure can provide the best mechanical stability in the meniscus and the strongest binding force in the damaged area. Meniscus injuries that are unable to be sutured are generally treated by meniscus merotomy and meniscus resection [86]. Allograft meniscus transplantation and synthetic materials have been applied clinically and have shown better prevention of knee joint degeneration compared with meniscus resection [87, 88]. Numerous reports describing the use of stem cell-associated tissue engineering to treat meniscal injury have demonstrated advantages in meniscus regeneration, showing promise for future meniscus injury treatments $[89,90]$.

4.3. Intervertebral Disc. Many patients experience back pain (lifetime prevalence of up to 84\%) [91]. Although back pain is a complex disease that can be affected by multiple factors, the majority of back pain in patients is caused by acute injury and degeneration of the intervertebral disc [92]. The intervertebral disc is formed by the inner core of the nucleus pulposus (NP) and the annulus fibrosis, which surrounds the NP. The former consists of chondrocyte-like intervertebral disc cells, unarranged collagen, and gel-like matrix components that are rich in proteoglycans. NP consists of parallel collagen fibers that form a circular arrangement and fibroblast-like cells [93]. Most acute injury due to mechanical force causes the annulus fibrosis to fall apart, and herniated NP oppresses the surrounding tissues, resulting in clinical symptoms. The pathogenesis of intervertebral disc degeneration is unclear; however, the increased rate of intervertebral disc cell death, loss of the ECM, change of phenotype of the intervertebral disc cells, and excessive inflammatory reaction are thought to play a key role in intervertebral disc degeneration [94].

Acute damage and degeneration of the lumbar joints are treated mainly by conservative or surgical treatments. If conservative treatment fails, surgery can be attempted to relieve the neurothlipsis. However, these interventions are focused on alleviating symptoms, rather than constituting a regenerative treatment. In recent years, the introduction and development of bioregenerative therapies have delayed intervertebral disc degeneration and allowed for tissue repair (i.e., ECM repair and regeneration). Bioregenerative therapies include gene therapy, targeting of biological factors, microRNA (miRNA) treatment [95], and tissue engineering based on stem cells [2, 61]. Among those bioregenerative therapies, the percutaneous injection of MSCs has been used clinically and has had a remarkable effect on improving discogenic pain [96]. These technologies can change the metabolism in the microenvironment of intervertebral discs and allow for intervertebral disc tissue regeneration, while maintaining the original biomechanics of the spine [97]. Although few clinical studies have examined MSCs injection, they have proved their safety and feasibility for improving discogenic pain. However, more clinical research is needed to support these benefits [2]. 


\section{Regenerative Medicine in Cartilage Repair}

5.1. Microfracture. The theory of microfracture in articular cartilage regeneration is based on the assumption that pluripotent stem cells, which are mainly BMSCs from bone marrow, can reach the damaged area by microfracture gap [98]. At the end of the procedure, it is important to assess whether there are fat granules overflowing from the bone marrow to verify the correct hole depth. Microfracture technology is reported to work best when the damaged area is $2-4 \mathrm{~cm}^{2}$ [99]. This technology exploits the multipotent capability of stem cells and accomplishes cartilage repair at low cost and with little surgical damage. However, the method causes fibrous cartilage formation in the repaired tissue, rather than the hyaline cartilage found in normal articular cartilage, which affects the biological performance $[4,100]$.

5.2. Mosaicplasty. Mosaicplasty, also known as autologous osteochondral transplantation, employs osteochondral plugs removed from a non-weight-bearing region of the joint to fill the damaged area. First applied in 1997, mosaicplasty is not strictly considered as a regenerative technology, and it also runs the risk of early failure of transplantation. Moreover, this technology can only repair damaged areas $<4 \mathrm{~cm}^{2}$ [101]. Cartilage that forms in the damaged area by autologous osteochondral transplantation is the same hyaline cartilage as normal cartilage. Mosaicplasty technology gives better results than microfracture repairs, but ACI in turn has more advantages than mosaicplasty [102].

5.3. Scaffold. The use of scaffolding can provide a 3D microenvironment for cartilage cells, solving the problem of chondrocyte differentiation in monolayer cultures. The scaffold prevents loss of chondrocytes, which grow in oriented scaffolding that simulates the normal arrangement of chondrocytes and thus forms a bionic structure [103]. By means of their mechanical properties, scaffolds can provide benefits for patients in early rehabilitation. Scaffolding is one of the most important components of tissue engineering [104]. Combined with various cartilage-related cytokines, it can be used to raise autologous stem cells to complete tissue repair status in the damaged region, including stem cells from blood, synovial fluid, synovial tissues, and cartilage. Stem cells loaded on the scaffold can be induced in vivo under a specific microenvironment. With the continuous development of material science and the application of 3D printing technology to the field of tissue engineering, cartilage repair combined with scaffold materials offers a promising future direction for articular cartilage, meniscus, and intervertebral disc repair $[105,106]$.

5.4. ACI and MACI. First applied in 1994, ACI has been reported widely with its satisfactory long-term, mid-term clinical results and magnetic resonance imaging (MRI) result [5]. Patients receiving ACI are generally $<50$ years old, and the area of damage is $>1 \mathrm{~cm}^{2}$, and cartilage injury is a type caused by acute trauma [107]. Compared with preliminary stage, ACI has explored much more indications than before.
There is quite a challenge that cartilage damage repair has been reported with better clinical effectiveness, such as in patients with failed cartilage repair surgery [108], early stage OA [109], older age [110], complex patellofemoral lesions [111], deep osteochondral lesions, and OCD [112]. Peterson et al. summarized 224 cartilage damage patients who had been treated by ACI in the past 20 years [113]. The subjective scores have a significant increase compared with preoperation time. The report also points out that $74 \%$ of the patients feel better or stable and $92 \%$ of the patients are satisfied with their treatment. Despite subchondral cysts, osteophytes, bone marrow edema, and other common side effects, ACI still has an excellent clinical result in the long run. However, this procedure also has several shortcomings, such as a second incision during gaining periosteal patch, hypertrophy in the repair area, and chondrocyte leakage [114]. It has been reported that utilizing collagen I or III membrane instead of periosteal patch can avoid a second incision and reduce the incidence rate of hypertrophy. MACI can avoid the cell leakage problem with the 3D culture of the cell. But no matter ACI or MACI, the chondrocyte phenotype maintenance is still a formidable issue during cell culture. Compared with prolonged monolayer culture in ACI, MACI can provide a 3D-culture microenvironment for chondrocyte adhesion, proliferation, and matrix secretion to maintain the chondrocyte phenotype [115]. It has been reported that 3D-culture microenvironment [65] and coculture [116] of stem cells with chondrocytes can do better in chondrocyte phenotype maintenance, which is the key point to determine the clinical effects of ACI and MACI, which needs more studies in the future.

5.5. Stem Cells and the Effect of Stem Cells on Cartilage Repair. In the past decade, stem cell-based treatment has been applied widely, and the number of studies on this topic has increased rapidly. Today, such treatment is an important branch of regenerative medicine. Stem cells have two effects: they have the potential for multiple differentiation and they have paracrine and immunomodulatory abilities, which are both important features in cartilage regeneration using MSCs $[117,118]$. The fact that stem cells can differentiate into cartilage cells and that a scaffold can be utilized for cell attachment makes this system amenable to cartilage tissue engineering with stem cells in the clinic. Laboratory studies and clinical evidence show that stem cells are an efficient method for treating traumatic bone-cartilage injury [119]. Although the application of stem cells combined with scaffold materials, by using tissue engineering technology, can achieve a satisfactory repair effect, no studies have shown that the repair effect of stem cells is better than that of chondrocytes. The application of stem cells combined with scaffold, for tissue engineering of traumatic cartilage damage, has a satisfactory effect, but little success has been reported in terms of the repair of OA cartilage degeneration.

This treatment is based on the paracrine and immunomodulatory effects of stem cells. Most stem cell OA treatments involve injections to insert stem cells into the damaged area of the articular cavity. Meniscus injury is treated with 
articular cavity injection [120, 121], while intervertebral disc damage is treated with local injection $[122,123]$. Although the mechanism is not fully understood, the effect is clear, especially for the treatment of OA. Many pathological reports and randomized controlled trials have demonstrated therapeutic effects. Stem cells secrete mediators that promote endogenous growth, stimulate self-proliferation of progenitor cells, and inhibit chondrocyte apoptosis or cartilage degeneration, achieving cartilage regeneration and cartilage protection [124]. In addition, several studies have shown that the inflammatory response in the injured area inhibits damage repair by endogenous stem cells or progenitor cells (such as cartilage stem cells) [125].

\section{Clinical Applications of Stem Cell Therapy in Cartilage Repair}

Compared with ESCs and iPSCs, adult stem cells are more secure and are therefore applied first in clinical therapy. MSCs are the most representative adult stem cells and are used widely in clinical cartilage regeneration. MSCs can be derived from various sources, such as bone marrow, fat, placenta, umbilical cord blood, synovial membrane, peripheral blood, tendons, and cartilage. BMSCs, ADSCs, synovial mesenchymal stem cells (SMSCs), peripheral blood-derived mesenchymal stem cells (PBMSCs), and other stem cells have been applied in clinical cartilage damage repair with satisfactory results (Table 1). Table 2 summarizes the results of a PubMed database search for clinical trials involving stem cells in cartilage regeneration, published from 2000 until the end of June 2016. Several recent studies have investigated allogeneic BMSCs for treating OA, demonstrating their safety and effectiveness in cartilage repair. In addition, ADSCs have been studied in recent years in terms of cartilage repair. Compared with BMSCs, ADSCs have certain advantages in the treatment of cartilage damage. Osteoporosis causes a decline in the quantity and quality of BMSCs, but ADSCs can be used to address this condition. The safety of cartilage damage repair is higher when the stroma vascular fraction (SVF) is not cultured in vitro. After liposuction surgery, adipose tissue, in the form of medical waste, can be reused. The most attractive reason for using PBMSCs is that they are easily acquired and require only one-step surgery for cartilage repair. Few studies have described the use of SMSCs and chondrocyte-derived progenitor cells (CDPCs) to repair cartilage damage, and further clinical tests are required to clarify their advantages and disadvantages. CDPCs originate from cartilage tissue and have a superior ability to differentiate into cartilage. Tissues requiring repair generally include the meniscus of the knee joint and talus cartilage; damage to these regions is limited mainly to cartilage damage or early OA. Cells can be delivered using a variety of methods such as simple direct injection of MSCs, or MSCs mixed with hyaluronic acid (HA), PRP, or glue, as well as MSCs combined with scaffold.

Despite years of research, the use of stem cells in cartilage regeneration has not met expectations. MSCs possess an intrinsic differentiation program for endochondral bone formation [126]. Although researchers seek to avoid the hypertrophic fate of MSCs, they cannot yet create articular hyaline cartilage without the hypertrophic chondrocyte phenotype [69]. This challenge must be overcome to enable better cartilage regeneration using MSC-based tissue engineering. In addition, the use of stem cells in cartilage regeneration is limited to untreated or multiplication cultured stem cells. Although the feasibility of using stem cells in cartilage regeneration has been proved, few clinical studies have been reported because the induced cells are unstable [127] (i.e., they degenerate readily and lead to tumorigenesis). Therefore, more studies are needed to prove the safety of using stem cells to induce cartilage.

\section{Conclusions}

Stem cells research is an important fundamental research topic in cartilage regeneration. Although the role of stem cells in cartilage regeneration is certain, the mechanism underlying this process in cartilage repair is not yet clear. The full range of limitations and possibilities, with respect to clinical application of various stem cells, remains to be established, but the advantages of stem cells seem obvious. MSCs are the most widely applied stem cells in the field of cartilage regeneration, and their safety and effectiveness have been demonstrated in basic research and clinical studies. There are many clinical examples of stem cells showing a satisfactory curative effect in cartilage damage repair, but larger sample sizes and longer follow-up periods in clinical studies are required to test the effectiveness and safety of stem cells for cartilage repair.

\author{
Abbreviations \\ AC: Articular cartilage \\ ACI: Autologous chondrocyte implantation \\ ADSCs: Adipose-derived stem cells \\ BMI: Body mass index \\ BMSCs: Bone mesenchymal stem cells \\ CT: $\quad$ Computed tomography \\ CDPCs: Chondrocyte-derived progenitor cells \\ HA: Hyaluronic acid \\ KOOS: Knee injury and osteoarthritis outcome score \\ ICRS: International Cartilage Repair Society \\ MRI: Magnetic resonance imaging \\ OA: Osteoarthritis \\ PBSCs: Peripheral blood stem cells \\ PRP: $\quad$ Platelet-rich plasma \\ RCT: Randomized controlled trial \\ SVF: Stroma vascular fraction.
}

\section{Competing Interests}

The authors declare that there are no competing interests regarding the publication of this paper. 


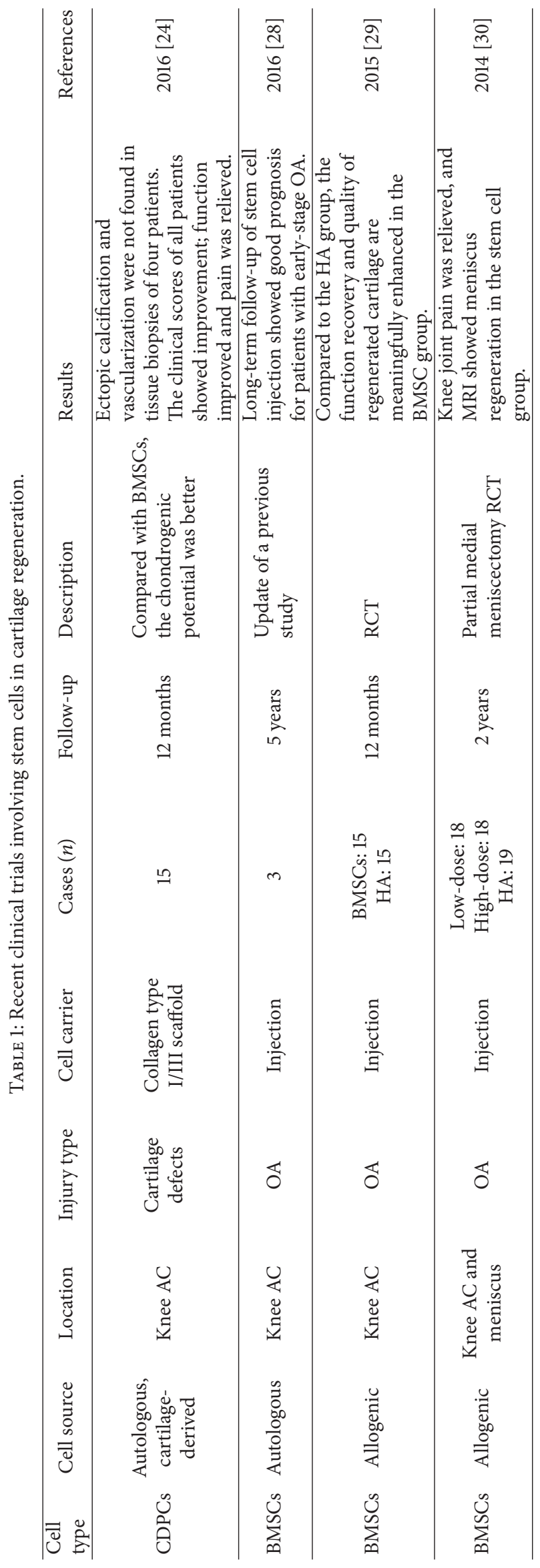




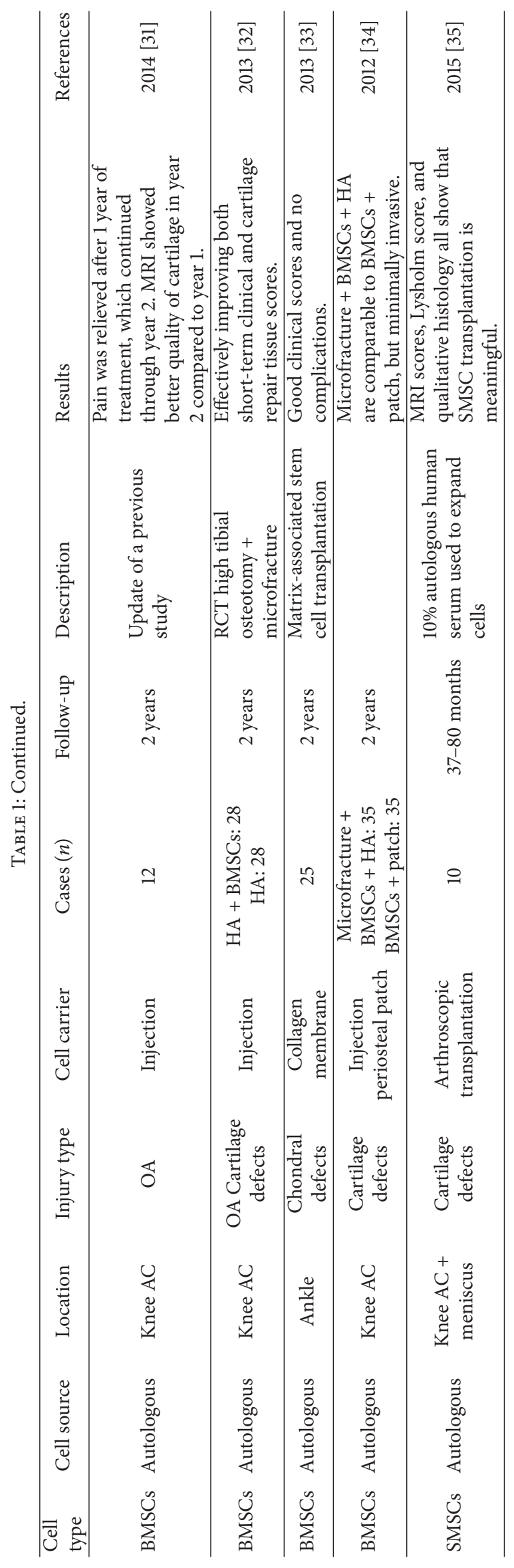




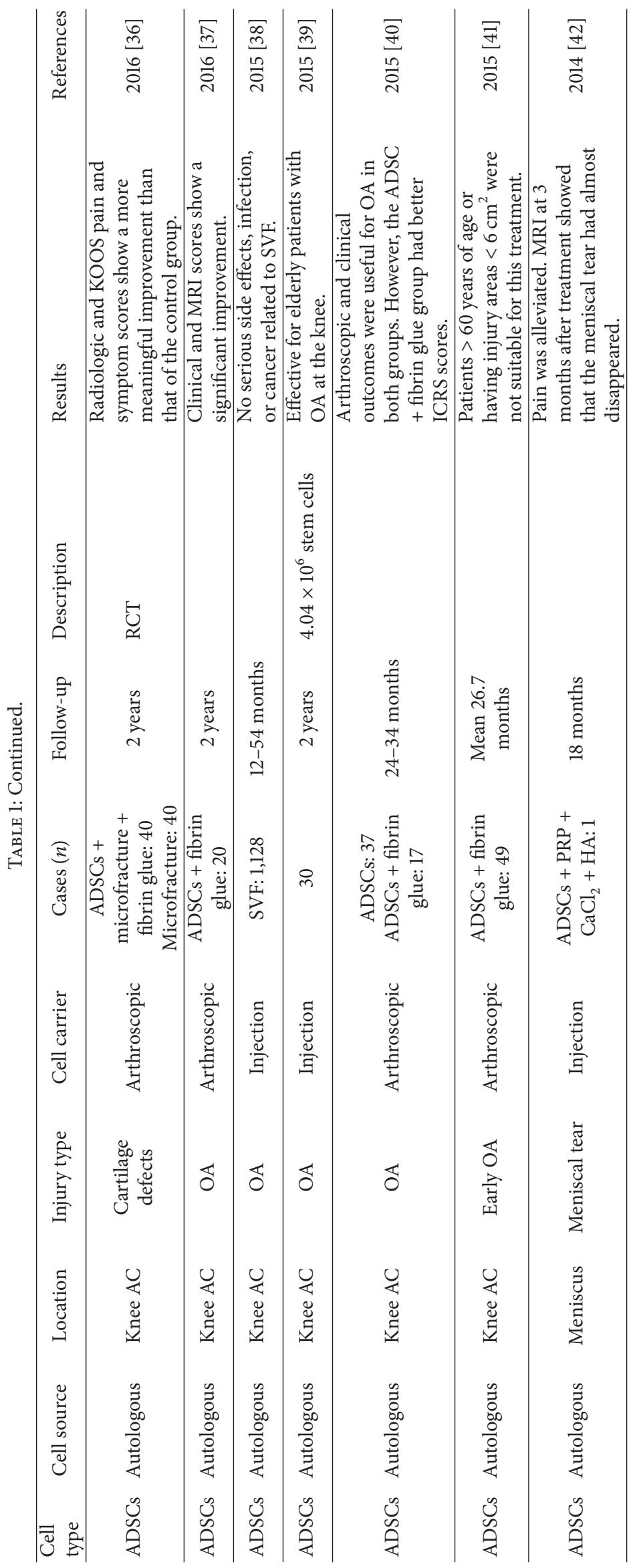




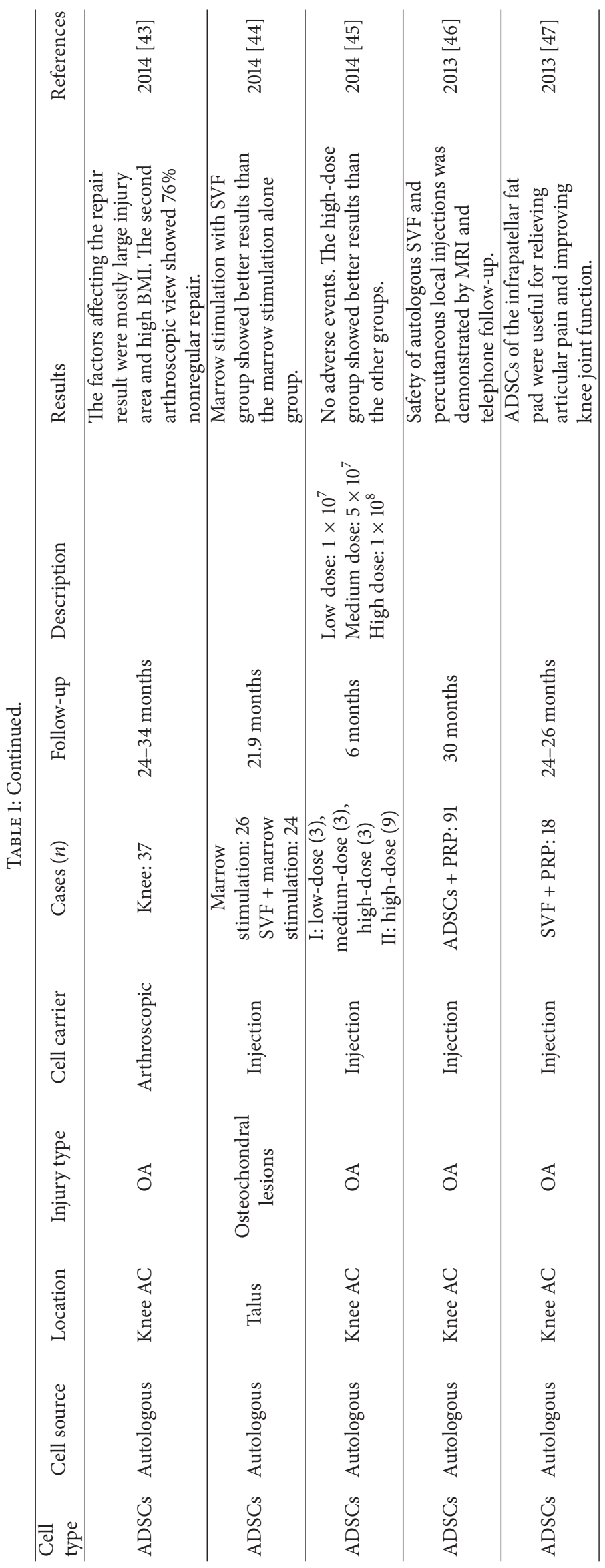




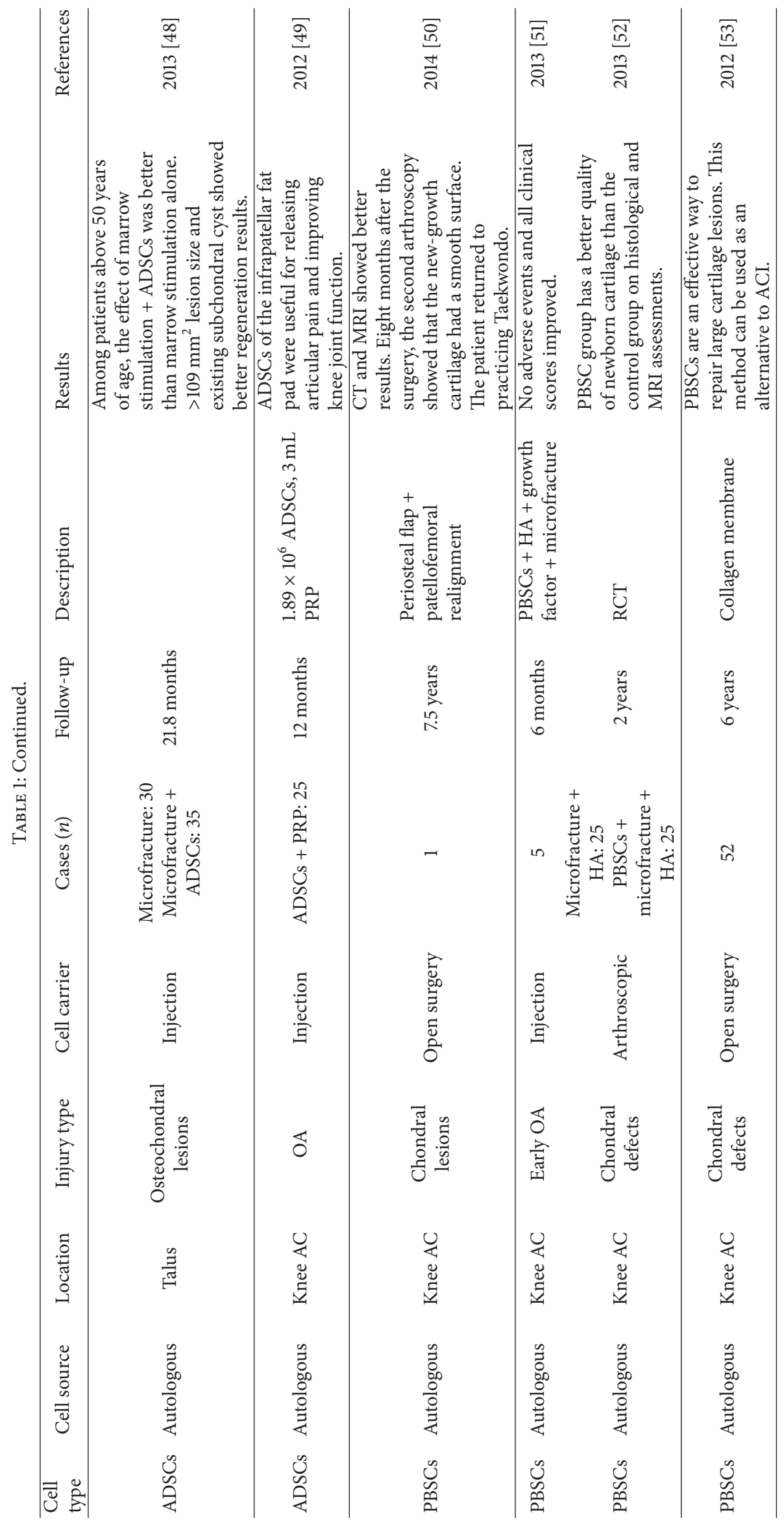


TABLE 2: Types of stem cells used clinically for cartilage regeneration past and present. This table shows the PubMed database search results for clinical trials involving stem cells in cartilage regeneration, published from 2000 until the end of June 2016 (number of papers).

\begin{tabular}{|c|c|c|c|c|c|c|}
\hline \multirow{2}{*}{ Year } & \multicolumn{5}{|c|}{ Cell type } & \multirow{2}{*}{ Tota } \\
\hline & BMSCs & ADSCs & PBSCs & SDSCs & CDPCs & \\
\hline 2002 & 1 & 0 & 0 & 0 & 0 & 1 \\
\hline 2004 & 1 & 0 & 0 & 0 & 0 & 1 \\
\hline 2005 & 1 & 0 & 0 & 0 & 0 & 1 \\
\hline 2007 & 2 & 0 & 0 & 0 & 0 & 2 \\
\hline 2008 & 1 & 0 & 0 & 0 & 0 & 1 \\
\hline 2010 & 2 & 0 & 0 & 0 & 0 & 2 \\
\hline 2011 & 2 & 1 & 1 & 0 & 0 & 4 \\
\hline 2012 & 2 & 1 & 1 & 0 & 0 & 4 \\
\hline 2013 & 2 & 2 & 2 & 0 & 0 & 6 \\
\hline 2014 & 2 & 4 & 1 & 0 & 0 & 7 \\
\hline 2015 & 1 & 4 & 0 & 1 & 0 & 6 \\
\hline 2016 & 1 & 2 & 0 & 0 & 1 & 4 \\
\hline Total & 18 & 14 & 5 & 1 & 1 & 39 \\
\hline
\end{tabular}

\section{Authors' Contributions}

Mingjie Wang and Zhiguo Yuan contributed equally to this work. All authors were involved in drafting the paper, and all authors approved the final version to be published.

\section{Acknowledgments}

This work was supported by the National High Technology Research and Development Program of China (2012AA020502, 2015AA020303), the National Natural Science Foundation of China (81472092, 21134004).

\section{References}

[1] M. B. Goldring and S. R. Goldring, "Articular cartilage and subchondral bone in the pathogenesis of osteoarthritis," Annals of the New York Academy of Sciences, vol. 1192, pp. 230-237, 2010.

[2] J. Zeckser, M. Wolff, J. Tucker, and J. Goodwin, "Multipotent mesenchymal stem cell treatment for discogenic low back pain and disc degeneration," Stem Cells International, vol. 2016, Article ID 3908389, 13 pages, 2016.

[3] E. Yelin, "Cost of musculoskeletal diseases: impact of work disability and functional decline," Journal of Rheumatology. Supplement, vol. 68, pp. 8-11, 2003.

[4] S. Oussedik, K. Tsitskaris, and D. Parker, "Treatment of articular cartilage lesions of the knee by microfracture or autologous chondrocyte implantation: a systematic review," Arthroscopy, vol. 31, no. 4, pp. 732-744, 2015.

[5] M. Brittberg, A. Lindahl, A. Nilsson, C. Ohlsson, O. Isaksson, and L. Peterson, "Treatment of deep cartilage defects in the knee with autologous chondrocyte transplantation," The New England Journal of Medicine, vol. 331, no. 14, pp. 889-895, 1994.

[6] P. Niemeyer, D. Albrecht, S. Andereya et al., "Autologous chondrocyte implantation (ACI) for cartilage defects of the knee: a guideline by the working group 'Clinical Tissue Regeneration' of the German Society of Orthopaedics and Trauma (DGOU)," Knee, vol. 23, no. 3, pp. 426-435, 2016.

[7] L. Duan, Y. Liang, B. Ma, W. Zhu, and D. Wang, "Epigenetic regulation in chondrocyte phenotype maintenance for cell-based cartilage repair," American Journal of Translational Research, vol. 7, no. 11, pp. 2127-2140, 2015.

[8] L. Duan, B. Ma, Y. Liang et al., "Cytokine networking of chondrocyte dedifferentiation in vitro and its implications for cell-based cartilage therapy," American Journal of Translational Research, vol. 7, no. 2, pp. 194-208, 2015.

[9] N. C. Foster, J. R. Henstock, Y. Reinwald, and A. J. El Haj, "Dynamic 3D culture: models of chondrogenesis and endochondral ossification," Birth Defects Research Part C: Embryo Today: Reviews, vol. 105, no. 1, pp. 19-33, 2015.

[10] S. Park and G.-I. Im, "Embryonic stem cells and induced pluripotent stem cells for skeletal regeneration," Tissue Engineering Part B: Reviews, vol. 20, no. 5, pp. 381-391, 2014.

[11] G. M. Hoben, V. P. Willard, and K. A. Athanasiou, "Fibrochondrogenesis of hESCs: growth factor combinations and cocultures," Stem Cells and Development, vol. 18, no. 2, pp. 283292, 2009.

[12] J. Toguchida, "Bone and stem cells. Advancement of regenerative medicine in the locomotive system using iPS cells," Clinical Calcium, vol. 24, no. 4, pp. 587-592, 2014.

[13] J. Dulak, K. Szade, A. Szade, W. Nowak, and A. Józkowicz, "Adult stem cells: hopes and hypes of regenerative medicine," Acta Biochimica Polonica, vol. 62, no. 3, pp. 329-337, 2015.

[14] A. Cheng, T. E. Hardingham, and S. J. Kimber, "Generating cartilage repair from pluripotent stem cells," Tissue Engineering B: Reviews, vol. 20, no. 4, pp. 257-266, 2014.

[15] S. Pacini, "Deterministic and stochastic approaches in the clinical application of mesenchymal stromal cells (MSCs)," Frontiers in Cell and Developmental Biology, vol. 2, article 50, 2014.

[16] G. P. Dowthwaite, J. C. Bishop, S. N. Redman et al., "The surface of articular cartilage contains a progenitor cell populations," Journal of Cell Science, vol. 117, no. 6, pp. 889-897, 2004.

[17] S. Chen, B. H. Lee, and Y. Bae, "Notch signaling in skeletal stem cells," Calcified Tissue International, vol. 94, no. 1, pp. 68-77, 2014.

[18] R. Williams, I. M. Khan, K. Richardson et al., "Identification and clonal characterisation of a progenitor cell sub-population in normal human articular cartilage," PLoS ONE, vol. 5, no. 10, Article ID e13246, 2010.

[19] S. Koelling, J. Kruegel, M. Irmer et al., "Migratory chondrogenic progenitor cells from repair tissue during the later stages of human osteoarthritis," Cell Stem Cell, vol. 4, no. 4, pp. 324-335, 2009.

[20] Y. Yu, H. Zheng, J. A. Buckwalter, and J. A. Martin, "Single cell sorting identifies progenitor cell population from full thickness bovine articular cartilage," Osteoarthritis and Cartilage, vol. 22, no. 9, pp. 1318-1326, 2014.

[21] C. Zhou, H. Zheng, D. Seol, Y. Yu, and J. A. Martin, "Gene expression profiles reveal that chondrogenic progenitor cells and synovial cells are closely related," Journal of Orthopaedic Research, vol. 32, no. 8, pp. 981-988, 2014.

[22] H. E. McCarthy, J. J. Bara, K. Brakspear, S. K. Singhrao, and C. W. Archer, "The comparison of equine articular cartilage progenitor cells and bone marrow-derived stromal cells as potential cell sources for cartilage repair in the horse," Veterinary Journal, vol. 192, no. 3, pp. 345-351, 2012. 
[23] D. Studer, C. Millan, E. Öztürk, K. Maniura-Weber, and M. Zenobi-Wong, "Molecular and biophysical mechanisms regulating hypertrophic differentiation in chondrocytes and mesenchymal stem cells," European Cells and Materials, vol. 24, pp. 118-135, 2012.

[24] Y. Jiang, Y. Cai, W. Zhang et al., "Human cartilage-derived progenitor cells from committed chondrocytes for efficient cartilage repair and regeneration," Stem Cells Translational Medicine, vol. 5, no. 6, pp. 733-744, 2016.

[25] H. Huang, S. Wang, J. Gui, and H. Shen, "A study to identify and characterize the stem/progenitor cell in rabbit meniscus," Cytotechnology, vol. 68, no. 5, pp. 2083-2103, 2016.

[26] C. Sang, X. Cao, F. Chen, X. Yang, and Y. Zhang, "Differential characterization of two kinds of stem cells isolated from rabbit nucleus pulposus and annulus fibrosus," Stem Cells International, vol. 2016, Article ID 8283257, 14 pages, 2016.

[27] Y. Jiang and R. S. Tuan, "Origin and function of cartilage stem/progenitor cells in osteoarthritis," Nature Reviews Rheumatology, vol. 11, no. 4, pp. 206-212, 2015.

[28] F. Davatchi, B. Sadeghi Abdollahi, M. Mohyeddin, and B. Nikbin, "Mesenchymal stem cell therapy for knee osteoarthritis: 5 years follow-up of three patients," International Journal of Rheumatic Diseases, vol. 19, no. 3, pp. 219-225, 2016.

[29] A. Vega, M. A. Martín-Ferrero, F. D. Canto et al., "Treatment of knee osteoarthritis with allogeneic bone marrow mesenchymal stem cells: a randomized controlled trial," Transplantation, vol. 99, no. 8, pp. 1681-1690, 2015.

[30] C. T. Vangsness Jr., J. Farr II, J. Boyd, D. T. Dellaero, C. R. Mills, and M. LeRoux-Williams, "Adult human mesenchymal stem cells delivered via intra-articular injection to the knee following partial medial meniscectomy: a randomized, doubleblind, controlled study," The Journal of Bone \& Joint SurgeryAmerican Volume, vol. 96, no. 2, pp. 90-98, 2014.

[31] L. Orozco, A. Munar, R. Soler et al., "Treatment of knee osteoarthritis with autologous mesenchymal stem cells: twoyear follow-up results," Transplantation, vol. 97, no. 11, pp. e66e68, 2014.

[32] K. L. Wong, K. B. L. Lee, B. C. Tai, P. Law, E. H. Lee, and J. H. P. Hui, "Injectable cultured bone marrow-derived mesenchymal stem cells in varus knees with cartilage defects undergoing high tibial osteotomy: a prospective, randomized controlled clinical trial with 2 years' follow-up," Arthroscopy, vol. 29, no. 12, pp. 2020-2028, 2013.

[33] M. Richter and S. Zech, "Matrix-associated stem cell transplantation (MAST) in chondral defects of foot and ankle is effective," Foot and Ankle Surgery, vol. 19, no. 2, pp. 84-90, 2013.

[34] K. B. L. Lee, V. T. Z. Wang, Y. H. Chan, and J. H. P. Hui, "A novel, minimally-invasive technique of cartilage repair in the human knee using arthroscopic microfracture and injections of mesenchymal stem cells and hyaluronic acid-a prospective comparative study on safety and short-term efficacy," Annals of the Academy of Medicine Singapore, vol. 41, no. 11, pp. 511-517, 2012.

[35] I. Sekiya, T. Muneta, M. Horie, and H. Koga, "Arthroscopic transplantation of synovial stem cells improves clinical outcomes in knees with cartilage defects," Clinical Orthopaedics and Related Research, vol. 473, no. 7, pp. 2316-2326, 2015.

[36] Y.-G. Koh, O.-R. Kwon, Y.-S. Kim, Y.-J. Choi, and D.-H. Tak, "Adipose-derived mesenchymal stem cells with microfracture versus microfracture alone: 2-year follow-up of a prospective randomized trial," Arthroscopy, vol. 32, no. 1, pp. 97-109, 2016.
[37] Y. S. Kim, Y. J. Choi, S. W. Lee et al., "Assessment of clinical and mri outcomes after mesenchymal stem cell implantation in patients with knee osteoarthritis: a prospective study," Osteoarthritis and Cartilage, vol. 24, no. 2, pp. 237-245, 2016.

[38] J. Michalek, R. Moster, L. Lukac et al., "Autologous adipose tissue-derived stromal vascular fraction cells application in patients with osteoarthritis," Cell Transplantation, 2015.

[39] Y.-G. Koh, Y.-J. Choi, S.-K. Kwon, Y.-S. Kim, and J.-E. Yeo, "Clinical results and second-look arthroscopic findings after treatment with adipose-derived stem cells for knee osteoarthritis," Knee Surgery, Sports Traumatology, Arthroscopy, vol. 23, no. 5, pp. 1308-1316, 2015.

[40] Y. S. Kim, Y. J. Choi, D. S. Suh et al., "Mesenchymal stem cell implantation in osteoarthritic knees: is fibrin glue effective as a scaffold?" The American Journal of Sports Medicine, vol. 43, no. 1, pp. 176-185, 2015.

[41] Y. S. Kim, Y. J. Choi, and Y. G. Koh, "Mesenchymal stem cell implantation in knee osteoarthritis: an assessment of the factors influencing clinical outcomes," The American Journal of Sports Medicine, vol. 43, no. 9, pp. 2293-2301, 2015.

[42] J. Pak, J. H. Lee, and S. H. Lee, "Regenerative repair of damaged meniscus with autologous adipose tissue-derived stem cells," BioMed Research International, vol. 2014, Article ID 436029, 10 pages, 2014.

[43] Y. G. Koh, Y. J. Choi, O. R. Kwon, and Y. S. Kim, "Second-look arthroscopic evaluation of cartilage lesions after mesenchymal stem cell implantation in osteoarthritic knees," The American Journal of Sports Medicine, vol. 42, no. 7, pp. 1628-1637, 2014.

[44] Y. S. Kim, H. J. Lee, Y. J. Choi, Y. I. Kim, and Y. G. Koh, “Does an injection of a stromal vascular fraction containing adiposederived mesenchymal stem cells influence the outcomes of marrow stimulation in osteochondral lesions of the talus? A clinical and magnetic resonance imaging study," American Journal of Sports Medicine, vol. 42, no. 10, pp. 2424-2434, 2014.

[45] C. H. Jo, Y. G. Lee, W. H. Shin et al., "Intra-articular injection of mesenchymal stem cells for the treatment of osteoarthritis of the knee: a proof-of-concept clinical trial," Stem Cells, vol. 32, no. 5, pp. 1254-1266, 2014.

[46] J. Pak, J.-J. Chang, J. H. Lee, and S. H. Lee, "Safety reporting on implantation of autologous adipose tissue-derived stem cells with platelet-rich plasma into human articular joints," $B M C$ Musculoskeletal Disorders, vol. 14, article 337, 2013.

[47] Y.-G. Koh, S.-B. Jo, O.-R. Kwon et al., "Mesenchymal stem cell injections improve symptoms of knee osteoarthritis," Arthroscopy, vol. 29, no. 4, pp. 748-755, 2013.

[48] Y. S. Kim, E. H. Park, Y. C. Kim, and Y. G. Koh, "Clinical outcomes of mesenchymal stem cell injection with arthroscopic treatment in older patients with osteochondral lesions of the talus," The American Journal of Sports Medicine, vol. 41, no. 5, pp. 1090-1099, 2013.

[49] Y.-G. Koh and Y.-J. Choi, "Infrapatellar fat pad-derived mesenchymal stem cell therapy for knee osteoarthritis," Knee, vol. 19, no. 6, pp. 902-907, 2012.

[50] W.-L. Fu, Y.-F. Ao, X.-Y. Ke et al., "Repair of large full-thickness cartilage defect by activating endogenous peripheral blood stem cells and autologous periosteum flap transplantation combined with patellofemoral realignment," Knee, vol. 21, no. 2, pp. 609612, 2014

[51] T. Turajane, U. Chaweewannakorn, V. Larbpaiboonpong et al., "Combination of intra-articular autologous activated peripheral blood stem cells with growth factor addition/ preservation 
and hyaluronic acid in conjunction with arthroscopic microdrilling mesenchymal cell stimulation Improves quality of life and regenerates articular cartilage in early osteoarthritic knee disease," Journal of the Medical Association of Thailand, vol. 96, no. 5, pp. 580-588, 2013.

[52] K.-Y. Saw, A. Anz, C. S.-Y. Jee et al., "Articular cartilage regeneration with autologous peripheral blood stem cells versus hyaluronic acid: a randomized controlled trial," ArthroscopyJournal of Arthroscopic and Related Surgery, vol. 29, no. 4, pp. 684-694, 2013.

[53] J. Skowroński, R. Skowroński, and M. Rutka, "Cartilage lesions of the knee treated with blood mesenchymal stem cellsresults," Ortopedia Traumatologia Rehabilitacja, vol. 14, no. 6, pp. 569-577, 2012.

[54] W. S. Toh, E. H. Lee, and T. Cao, "Potential of human embryonic stem cells in cartilage tissue engineering and regenerative medicine," Stem Cell Reviews and Reports, vol. 7, no. 3, pp. 544559, 2011.

[55] A. Cheng, Z. Kapacee, J. Peng et al., "Cartilage repair using human embryonic stem cell-derived chondroprogenitors," Stem Cells Translational Medicine, vol. 3, no. 11, pp. 1287-1294, 2014.

[56] C. Fu, Z. Yan, H. Xu et al., "Isolation, identification and differentiation of human embryonic cartilage stem cells," Cell Biology International, vol. 39, no. 7, pp. 777-787, 2015.

[57] K. Takahashi and S. Yamanaka, "Induction of pluripotent stem cells from mouse embryonic and adult fibroblast cultures by defined factors," Cell, vol. 126, no. 4, pp. 663-676, 2006.

[58] R. M. Guzzo and H. Drissi, "Differentiation of human induced pluripotent stem cells to chondrocytes," Methods in Molecular Biology, vol. 1340, pp. 79-95, 2015.

[59] N. Tsumaki, M. Okada, and A. Yamashita, "iPS cell technologies and cartilage regeneration," Bone, vol. 70, pp. 48-54, 2015.

[60] R. M. Guzzo, V. Scanlon, A. Sanjay, R.-H. Xu, and H. Drissi, "Establishment of human cell type-specific iPS cells with enhanced chondrogenic potential," Stem Cell Reviews and Reports, vol. 10, no. 6, pp. 820-829, 2014.

[61] S. M. Richardson, G. Kalamegam, P. N. Pushparaj et al., "Mesenchymal stem cells in regenerative medicine: focus on articular cartilage and intervertebral disc regeneration," Methods, vol. 99, pp. 69-80, 2016.

[62] M. B. Goldring, K. Tsuchimochi, and K. Ijiri, "The control of chondrogenesis," Journal of Cellular Biochemistry, vol. 97, no. 1, pp. 33-44, 2006.

[63] M. Bhattacharjee, J. Coburn, M. Centola et al., "Tissue engineering strategies to study cartilage development, degeneration and regeneration," Advanced Drug Delivery Reviews, vol. 84, pp. 107122, 2015.

[64] M. Zhou, X. Yuan, H. Yin, and J. E. Gough, "Restoration of chondrocytic phenotype on a two-dimensional micropatterned surface," Biointerphases, vol. 10, no. 1, Article ID 011003, 2015.

[65] J. A. Panadero, S. Lanceros-Mendez, and J. L. G. Ribelles, "Differentiation of mesenchymal stem cells for cartilage tissue engineering: individual and synergetic effects of three-dimensional environment and mechanical loading," Acta Biomaterialia, vol. 33, pp. 1-12, 2016.

[66] K. M. Hubka, R. L. Dahlin, V. V. Meretoja, F. K. Kasper, and A. G. Mikos, "Enhancing chondrogenic phenotype for cartilage tissue engineering: monoculture and coculture of articular chondrocytes and mesenchymal stem cells," Tissue Engineering Part B: Reviews, vol. 20, no. 6, pp. 641-654, 2014.
[67] J. C. Sherwood, J. Bertrand, S. E. Eldridge, and F. Dell'accio, "Cellular and molecular mechanisms of cartilage damage and repair," Drug Discovery Today, vol. 19, no. 8, pp. 1172-1177, 2014.

[68] P. Bhattaram and U. Chandrasekharan, "The joint synovium: a critical determinant of articular cartilage fate in inflammatory joint diseases," Seminars in Cell \& Developmental Biology, 2016.

[69] S. Chen, P. Fu, R. Cong, H. Wu, and M. Pei, "Strategies to minimize hypertrophy in cartilage engineering and regeneration," Genes and Diseases, vol. 2, no. 1, pp. 76-95, 2015.

[70] S. P. Grogan, X. Chen, S. Sovani et al., "Influence of cartilage extracellular matrix molecules on cell phenotype and neocartilage formation," Tissue Engineering_Part A, vol. 20, no. 1-2, pp. 264-274, 2014

[71] T. A. Stupina, M. A. Stepanov, and M. P. Teplen'kii, "Role of subchondral bone in the restoration of articular cartilage," Bulletin of Experimental Biology and Medicine, vol. 158, no. 6, pp. 820-823, 2015.

[72] Z. Wang, H. Qin, Z. Feng, and Y. Zhao, "Platelet-rich plasma gel composited with nondegradable porous polyurethane scaffolds as a potential auricular cartilage alternative," Journal of Biomaterials Applications, vol. 30, no. 7, pp. 889-899, 2016.

[73] A. J. Krych, D. H. Nawabi, N. A. Farshad-Amacker et al., "Bone marrow concentrate improves early cartilage phase maturation of a scaffold plug in the knee: a comparative magnetic resonance imaging analysis to platelet-rich plasma and control," American Journal of Sports Medicine, vol. 44, no. 1, pp. 91-98, 2016.

[74] A. G. Bajpayee, M. Scheu, A. J. Grodzinsky, and R. M. Porter, "A rabbit model demonstrates the influence of cartilage thickness on intra-articular drug delivery and retention within cartilage," Journal of Orthopaedic Research, vol. 33, no. 5, pp. 660-667, 2015.

[75] K. Takayama, Y. Kawakami, M. Kobayashi et al., "Local intra-articular injection of rapamycin delays articular cartilage degeneration in a murine model of osteoarthritis," Arthritis research \& therapy, vol. 16, no. 6, article 482, 2014.

[76] K. Chen, N. Zhang, L. Ding, W. Zhang, J. Hu, and S. Zhu, "Early intra-articular injection of alendronate reduces cartilage changes and subchondral bone loss in rat temporomandibular joints after ovariectomy," International Journal of Oral and Maxillofacial Surgery, vol. 43, no. 8, pp. 996-1004, 2014.

[77] K. Chareancholvanich, C. Pornrattanamaneewong, and R. Narkbunnam, "Increased cartilage volume after injection of hyaluronic acid in osteoarthritis knee patients who underwent high tibial osteotomy," Knee Surgery, Sports Traumatology, Arthroscopy, vol. 22, no. 6, pp. 1415-1423, 2014.

[78] M. Hayashi, T. Muneta, T. Takahashi, Y.-J. Ju, K. Tsuji, and I. Sekiya, "Intra-articular injections of bone morphogenetic protein-7 retard progression of existing cartilage degeneration," Journal of Orthopaedic Research, vol. 28, no. 11, pp. 1502-1506, 2010.

[79] H. Yazdi, B. T. Nimavard, M. Shokrgozar et al., "An evaluation of the delayed effect of intra-articular injections of lidocaine ( $2 \%)$ on articular cartilage: an experimental study in rabbits," European Journal of Orthopaedic Surgery and Traumatology, vol. 24, no. 8, pp. 1557-1561, 2014.

[80] P. S. McCabe, N. Maricar, M. J. Parkes, D. T. Felson, and T. W. O'Neill, "The efficacy of intra-articular steroids in hip osteoarthritis: a systematic review," Osteoarthritis and Cartilage, vol. 24, no. 9, pp. 1509-1517, 2016.

[81] Evidence Development and Standards Branch and Health Quality Ontario, "Arthroscopic debridement of the knee: an evidence update," Ontario Health Technology Assessment Series, vol. 14, no. 13, pp. 1-43, 2014. 
[82] A. Badri and J. Burkhardt, "Arthroscopic debridement of unicompartmental arthritis. Fact or fiction?" Clinics in Sports Medicine, vol. 33, no. 1, pp. 23-41, 2014.

[83] Health Quality Ontario, "Arthroscopic lavage and debridement for osteoarthritis of the knee: an evidence-based analysis," Ontario Health Technology Assessment Series, vol. 5, no. 12, pp. 1-37, 2005.

[84] K. H. Fibel, H. J. Hillstrom, and B. C. Halpern, "State-of-the-Art management of knee osteoarthritis," World Journal of Clinical Cases, vol. 3, no. 2, pp. 89-101, 2015.

[85] W. Guo, S. Liu, Y. Zhu et al., "Advances and prospects in tissueengineered meniscal scaffolds for meniscus regeneration," Stem Cells International, vol. 2015, Article ID 517520, 13 pages, 2015.

[86] R. B. Souza, S. J. Wu, L. J. Morse, K. Subburaj, C. R. Allen, and B. T. Feeley, "Cartilage MRI relaxation times after arthroscopic partial medial meniscectomy reveal localized degeneration," Knee Surgery, Sports Traumatology, Arthroscopy, vol. 23, no. 1, pp. 188-197, 2014.

[87] J. J. Rongen, G. Hannink, T. G. van Tienen, J. van Luijk, and C. R. Hooijmans, "The protective effect of meniscus allograft transplantation on articular cartilage: a systematic review of animal studies," Osteoarthritis and Cartilage, vol. 23, no. 8, pp. 1242-1253, 2015.

[88] D.-H. Lee, C.-R. Lee, J.-H. Jeon, K.-A. Kim, and S.-I. Bin, "Graft extrusion in both the coronal and sagittal planes is greater after medial compared with lateral meniscus allograft transplantation but is unrelated to early clinical outcomes," American Journal of Sports Medicine, vol. 43, no. 1, pp. 213-219, 2015.

[89] W. G. Rodkey, J. R. Steadman, and S.-T. Li, "A clinical study of collagen meniscus implants to restore the injured meniscus," Clinical Orthopaedics and Related Research, no. 367, pp. S281S292, 1999.

[90] Y. Zhang, P. Li, H. Wang, Y. Wang, K. Song, and T. Li, "Research progress on reconstruction of meniscus in tissue engineering," The Journal of Sports Medicine and Physical Fitness, 2016.

[91] F. Balagué, A. F. Mannion, F. Pellisé, and C. Cedraschi, "Nonspecific low back pain," The Lancet, vol. 379, no. 9814, pp. 482491, 2012.

[92] J. W. Geurts, J.-W. Kallewaard, A. Kessels et al., "Efficacy and cost-effectiveness of intradiscal methylene blue injection for chronic discogenic low back pain: study protocol for a randomized controlled trial," Trials, vol. 16, no. 1, article 532, 2015.

[93] F. Clarençon, B. Law-Ye, P. Bienvenot, É. Cormier, and J. Chiras, "The degenerative spine," Magnetic Resonance Imaging Clinics of North America, vol. 24, no. 3, pp. 495-513, 2016.

[94] C. Feng, H. Liu, M. Yang, Y. Zhang, B. Huang, and Y. Zhou, "Disc cell senescence in intervertebral disc degeneration: causes and molecular pathways," Cell Cycle, vol. 15, no. 13, pp. 1674$1684,2016$.

[95] C. Wang, W.-J. Wang, Y.-G. Yan et al., "MicroRNAs: new players in intervertebral disc degeneration," Clinica Chimica Acta, vol. 450, pp. 333-341, 2015.

[96] L. Orozco, R. Soler, C. Morera, M. Alberca, A. Sánchez, and J. García-Sancho, "Intervertebral disc repair by autologous mesenchymal bone marrow cells: A Pilot Study," Transplantation, vol. 92, no. 7, pp. 822-828, 2011.

[97] Q. Yang, H.-W. Xu, S. Hurday, and B.-S. Xu, "Construction strategy and progress of whole intervertebral disc tissue engineering," Orthopaedic Surgery, vol. 8, no. 1, pp. 11-18, 2016.
[98] H. H. Passler, "Microfracture for treatment of cartilage detects," Zentralblatt für Chirurgie, vol. 125, no. 6, pp. 500-504, 2000.

[99] D. L. Richter, R. C. Schenck, D. C. Wascher, and G. Treme, "Knee articular cartilage repair and restoration techniques: a review of the literature," Sports Health, vol. 8, no. 2, pp. 153-160, 2016.

[100] P. Abdel-Sayed and D. P. Pioletti, "Strategies for improving the repair of focal cartilage defects," Nanomedicine, vol. 10, no. 18, pp. 2893-2905, 2015.

[101] L. Hangody, G. Kish, Z. Kárpáti, I. Szerb, and I. Udvarhelyi, "Arthroscopic autogenous osteochondral mosaicplasty for the treatment of femoral condylar articular defects. A preliminary report," Knee Surgery, Sports Traumatology, Arthroscopy, vol. 5, no. 4, pp. 262-267, 1997.

[102] C. Duif, M. A. Koutah, O. Ackermann et al., "Combination of autologous chondrocyte implantation (ACI) and osteochondral autograft transfer system (OATS) for surgical repair of larger cartilage defects of the knee joint. A review illustrated by a case report," Technology and Health Care, vol. 23, no. 5, pp. 531-537, 2015.

[103] A. Mellati, M. V. Kiamahalleh, S. H. Madani et al., "Poly(Nisopropylacrylamide) hydrogel/chitosan scaffold hybrid for three-dimensional stem cell culture and cartilage tissue engineering," Journal of Biomedical Materials Research-Part A, 2016.

[104] S. Fischer and A. Kisser, "Single-step scaffold-based cartilage repair in the knee: a systematic review," Journal of Orthopaedics, vol. 13, no. 4, pp. 246-253, 2016.

[105] D. O. Visscher, E. J. Bos, M. Peeters et al., "Cartilage tissue engineering: preventing tissue scaffold contraction using a 3Dprinted polymeric cage," Tissue Engineering - Part C: Methods, vol. 22, no. 6, pp. 573-584, 2016.

[106] A. D. Olubamiji, Z. Izadifar, J. L. Si, D. M. Cooper, B. F. Eames, and D. X. Chen, "Modulating mechanical behaviour of 3Dprinted cartilage-mimetic PCL scaffolds: influence of molecular weight and pore geometry," Biofabrication, vol. 8, no. 2, Article ID 025020, 2016.

[107] G. Bentley, J. S. Bhamra, P. D. Gikas, J. A. Skinner, R. Carrington, and T. W. Briggs, "Repair of osteochondral defects in jointshow to achieve success," Injury, vol. 44, no. 1, pp. S3-S10, 2013.

[108] J. E. Browne, A. F. Anderson, R. Arciero et al., "Clinical outcome of autologous chondrocyte implantation at 5 years in US subjects," Clinical Orthopaedics and Related Research, no. 436, pp. 237-245, 2005.

[109] T. Minas, A. H. Gomoll, S. Solhpour, R. Rosenberger, C. Probst, and T. Bryant, "Autologous chondrocyte implantation for joint preservation in patients with early osteoarthritis," Clinical Orthopaedics and Related Research, vol. 468, no. 1, pp. 147-157, 2010.

[110] R. E. Rosenberger, A. H. Gomoll, T. Bryant, and T. Minas, "Repair of large chondral defects of the knee with autologous chondrocyte implantation in patients 45 years or older," American Journal of Sports Medicine, vol. 36, no. 12, pp. 2336-2344, 2008.

[111] J. Farr, "Autologous chondrocyte implantation improves patellofemoral cartilage treatment outcomes," Clinical Orthopaedics and Related Research, no. 463, pp. 187-194, 2007.

[112] L. Peterson, T. Minas, M. Brittberg, and A. Lindahl, "Treatment of osteochondritis dissecans of the knee with autologous chondrocyte transplantation: results at two to ten years," Journal of Bone and Joint Surgery-Series A, vol. 85, no. 1, pp. 17-24, 2003.

[113] L. Peterson, H. S. Vasiliadis, M. Brittberg, and A. Lindahl, "Autologous chondrocyte implantation: a long-term follow-up," 
The American Journal of Sports Medicine, vol. 38, no. 6, pp. 1117$1124,2010$.

[114] C. B. Foldager, J. Farr, and A. H. Gomoll, "Patients scheduled for chondrocyte implantation treatment with MACI have larger defects than those enrolled in clinical trials," Cartilage, vol. 7, no. 2, pp. 140-148, 2016.

[115] E. Kon, G. Filardo, A. Di Martino, and M. Marcacci, "ACI and MACI," The Journal of Knee Surgery, vol. 25, no. 1, pp. 17-22, 2012.

[116] F. Zhang, K. Su, Y. Fang, S. Sandhya, and D.-A. Wang, "A mixed co-culture of mesenchymal stem cells and transgenic chondrocytes in alginate hydrogel for cartilage tissue engineering," Journal of Tissue Engineering and Regenerative Medicine, vol. 9, no. 1, pp. 77-84, 2015.

[117] Y. Wu, J. Zhou, L. Bi et al., "Effects of bone marrow mesenchymal stem cells on the cardiac function and immune system of mice with endotoxemia," Molecular Medicine Reports, vol. 13, no. 6, pp. 5317-5325, 2016.

[118] A. Park, J. Barrera-Ramirez, I. Ranasinghe et al., "Use of statins to augment progenitor cell function in preclinical and clinical studies of regenerative therapy: a systematic review," Stem Cell Reviews and Reports, vol. 12, no. 3, pp. 327-339, 2016.

[119] G. Filardo, F. Perdisa, A. Roffi, M. Marcacci, and E. Kon, "Stem cells in articular cartilage regeneration," Journal of Orthopaedic Surgery and Research, vol. 11, no. 1, article 42, 2016.

[120] W. Shen, J. Chen, T. Zhu et al., "Osteoarthritis prevention through meniscal regeneration induced by intra-articular injection of meniscus stem cells," Stem Cells and Development, vol. 22, no. 14, pp. 2071-2082, 2013.

[121] Y. Qi, Z. Yang, Q. Ding, T. Zhao, Z. Huang, and G. Feng, “Targeted transplantation of iron oxide-labeled, adipose-derived mesenchymal stem cells in promoting meniscus regeneration following a rabbit massive meniscal defect," Experimental and Therapeutic Medicine, vol. 11, no. 2, pp. 458-466, 2016.

[122] D. Drazin, J. Rosner, P. Avalos, and F. Acosta, "Stem cell therapy for degenerative disc disease," Advances in Orthopedics, vol. 2012, Article ID 961052, 8 pages, 2012.

[123] B. J. C. Freeman, J. S. Kuliwaba, C. F. Jones et al., "Allogeneic mesenchymal precursor cells promote healing in postero-lateral annular lesions and improve indices of lumbar intervertebral disc degeneration in an ovine model," Spine, vol. 41, no. 17, pp. 1331-1339, 2016.

[124] Y.-M. Pers, M. Ruiz, D. Noël, and C. Jorgensen, "Mesenchymal stem cells for the management of inflammation in osteoarthritis: state of the art and perspectives," Osteoarthritis and Cartilage, vol. 23, no. 11, pp. 2027-2035, 2015.

[125] M. B. Murphy, K. Moncivais, and A. I. Caplan, "Mesenchymal stem cells: environmentally responsive therapeutics for regenerative medicine," Experimental and Molecular Medicine, vol. 45, article e54, 2013.

[126] M. M.-G. Sun and F. Beier, "Chondrocyte hypertrophy in skeletal development, growth, and disease," Birth Defects Research Part C-Embryo Today: Reviews, vol. 102, no. 1, pp. 74-82, 2014.

[127] R. A. Somoza, J. F. Welter, D. Correa, and A. I. Caplan, "Chondrogenic differentiation of mesenchymal stem cells: challenges and unfulfilled expectations," Tissue Engineering Part B: Reviews, vol. 20, no. 6, pp. 596-608, 2014. 

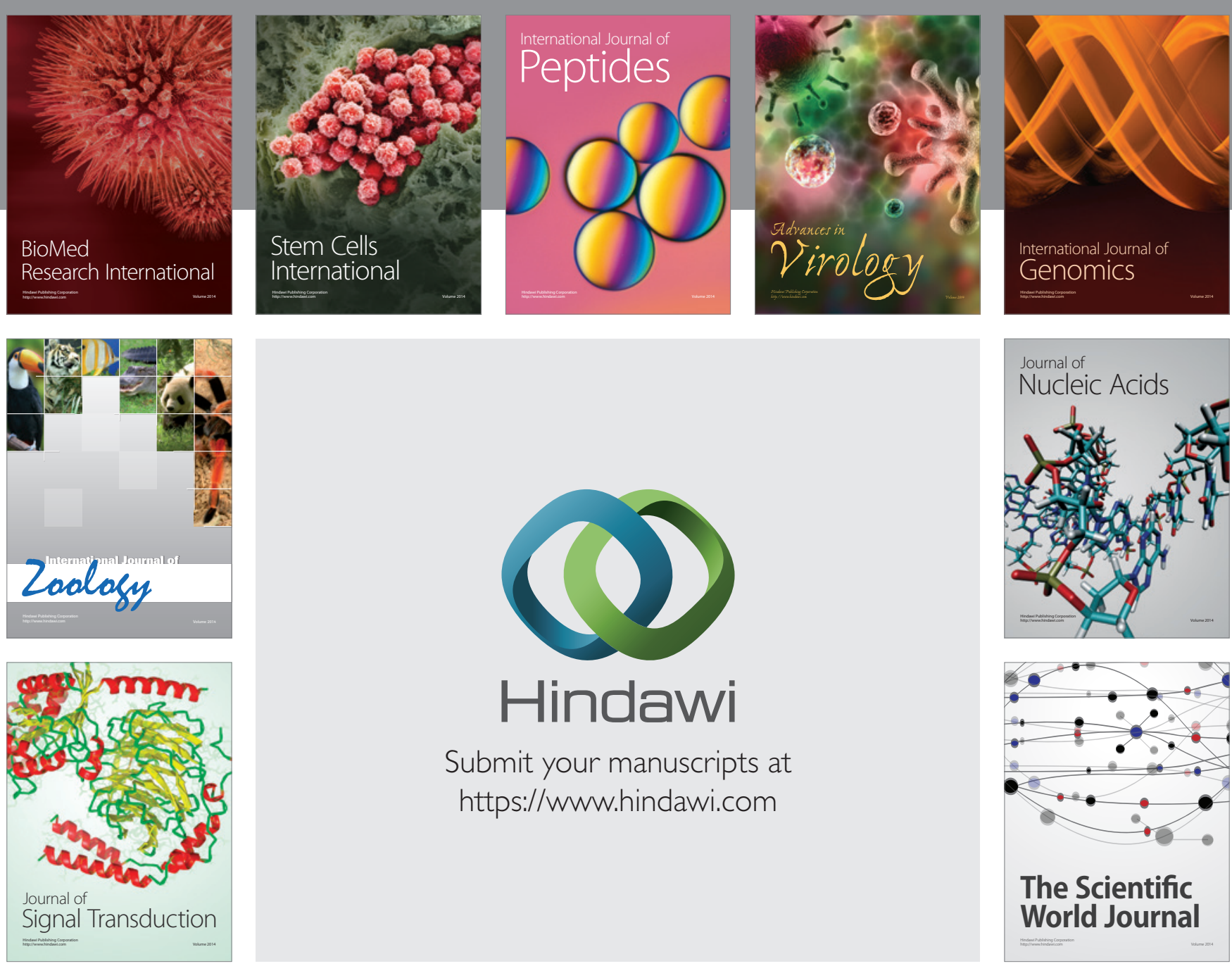

Submit your manuscripts at

https://www.hindawi.com
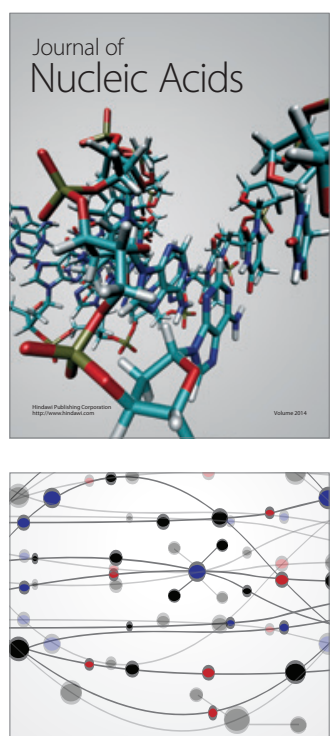

The Scientific World Journal
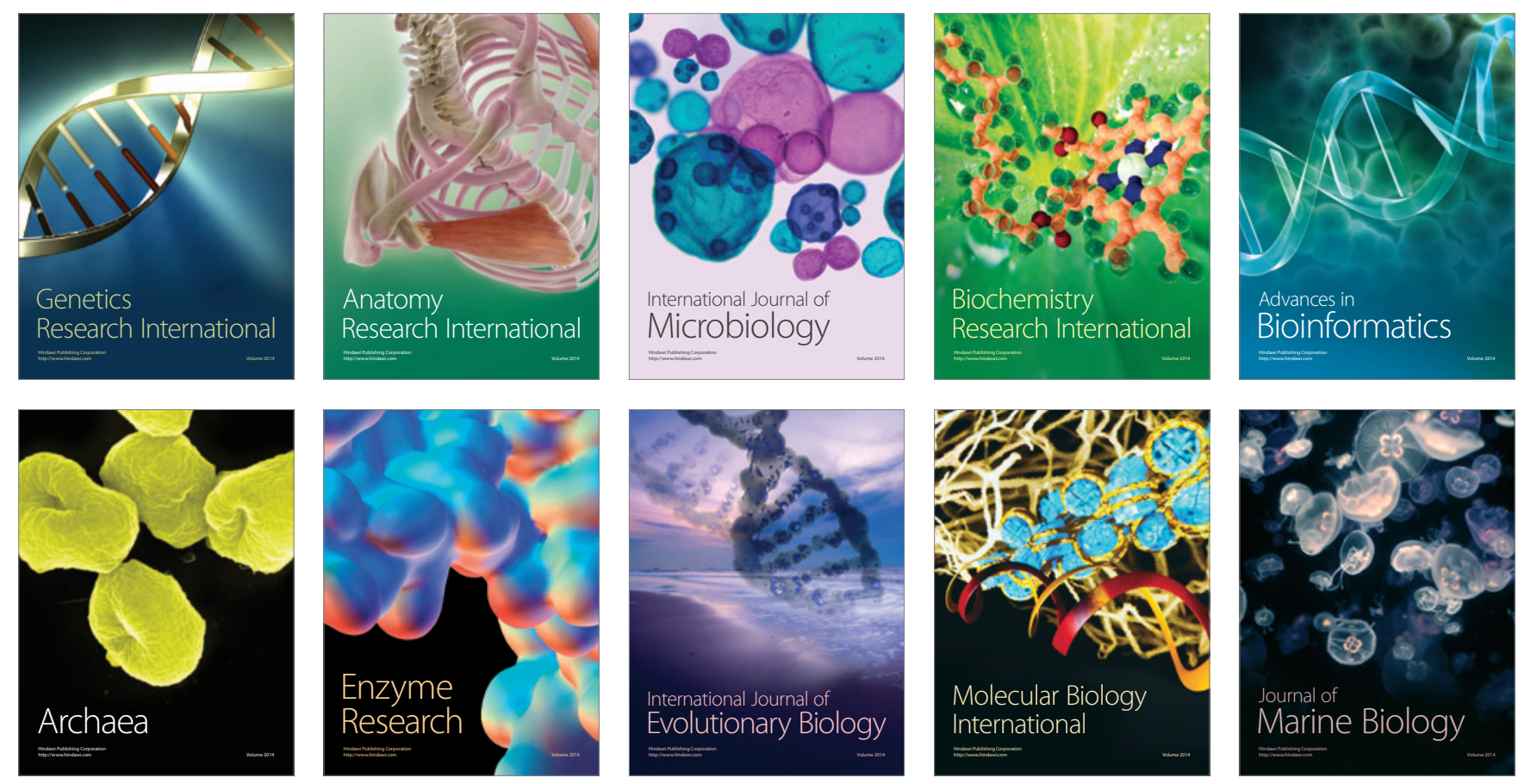